\title{
A Produção de Produtos Orgânicos e Agroecológicos no Sudoeste do Paraná ${ }^{1}$
}

\author{
La Producción de Productos Orgánicos en el Sudoeste del Paraná \\ The Production of Organic and Agroecological Products in the Southwest
of Paraná
}

Tiago Arcanjo Orben ${ }^{2}$

\begin{abstract}
Resumo
Esse trabalho procura refletir sobre a produção de produtos orgânicos e agroecológicos na região Sudoeste do Paraná, mais especificamente no município de Verê. Local onde fica localizada a Cooperativa dos Produtores Orgânicos e Agroecológicos do Sudoeste do Paraná - Coopervereda. A atenção dada a essa região e a esse município se deve por estar relacionada ao assunto abordado em meu projeto de Doutorado em História, o qual procura questionar a estrutura agrária e fundiária da região Sudoeste do Paraná. Assim, nos primeiros levantamentos constatou-se a significativa atuação, tanto, de cooperativas agrícolas e de crédito, que incentivam a produção de monoculturas, quanto, de centros de apoio e promoção da produção orgânica e agroecológica, como a Coopervereda. Deste modo, utilizando-se da metodologia oral, este trabalho expõe para debate as formas de atuação desta Cooperativa no município de Verê, com atenção especial para seu trabalho junto aos agricultores da região. Para tanto, será utilizada uma entrevista realizada com o agricultor Décio Cagnine, que produz em sua propriedade alimentos orgânicos, além de prestar assessoria a outros agricultores da região. A partir deste contexto, se sobrepõe para discussão as políticas públicas, que não só dão sustentação a tais agricultores, como também regram a inserção de práticas orgânicas e agroecológicas entre os pequenos proprietários desta região.
\end{abstract}

Palavras-Chave: Cooperativa dos Produtores Orgânicos e Agroecológicos do Sudoeste do Paraná Coopervereda; História Agrária; Memórias; Pequenas propriedades; Sudoeste do Paraná.

\section{Resumen}

Ese trabajo busca reflexionar sobre la producción de productos orgánicos y agroecológicos en la región del Sudoeste del Paraná, pero específicamente en el municipio de Verê. Sitio donde se queda ubicada la Cooperativa de los Productores Orgánicos y Agroecológicos del Paraná - Coopervereda. La atención puesta sobre esa región y ese municipio se debe por la relación que mantiene con el asunto de mi proyecto de Doctorado en Historia, que busca cuestionar la estructura agraria y territorial de la región Sudoeste del Paraná. De esa forma, en los primeros levantamientos se constató la importante actuación, no solamente, de cooperativas agrícolas y de préstamo, que incentiván a la producción de monocultivos, como también, de centros de apoyo y promoción de la producción orgánica y agroecológica, como la Coopervereda. De este modo, utilizándose de la metodología oral, este trabajo expone para discusión las formas de actuación de esta Cooperativa en el municipio de Verê, con atención especial para su trabajo junto a los productores agrícolas de la región. Para eso, se vá a utilizar una entrevista hecha con el agricultor Décio Cagnine, que produce en su propiedad alimentos orgánicos, además de prestar servicios de consultoria a outros productores de la región. Desde este contexto, se sobreponen para discusión las políticas públicas, que no solo dan suporte a estos agricultores, como también regulan la inserción de las prácticas orgánicas y agroecológicas entre los pequeños propietarios de esta región.

\footnotetext{
${ }^{1}$ Artigo apresentado no Simpósio Temático (Políticas públicas, diversidade cultural e descolonização) durante o II Seminário Latino-Americano de Estudos em Cultura - SEMLACult em Foz do Iguaçu/PR, Brasil, 2018.

${ }^{2}$ Doutor em História pelo Programa de Pós-Graduação em História - PPGH da Pontifícia Universidade Católica do Rio Grande do Sul-PUCRS, Porto Alegre, Rio Grande do Sul, Brasil. Orientador Prof. Dr. Luis Carlos dos Passos Martins. E-mail: “tiagoaorben@ gmail.com”.
} 
Palabras claves: Cooperativa de los Productores Orgánicos y Agroecológicos del Sudoeste del Paraná Coopervereda; Historia Agraria; Memorias; Pequeñas propiedades; Sudoeste del Paraná.

\begin{abstract}
This work aims to reflect about the production of organic and agroecological products in the Southwest region of Paraná, more specifically in the municipality of Verê, where is located the Cooperative of the Organic and Agroecological Producers of the Southwest of Paraná - Coopervereda. The attention given to this region is related to the subject addressed in my History $\mathrm{PhD}$ project, which aims to question the agrarian and land structure of the Southwest region of Paraná. Thus, the first surveys showed the significant performance of both agricultural and credit cooperatives, encouraging the production of monocultures, as well as centers for support and promotion of organic and agroecological production, such as Coopervereda. Thereby, using oral methodology, this paper exposes for debate the ways in which this cooperative operates in the municipality of Verê, with special attention to its work with farmers in the region. Therefore, it will be used an interview with the farmer Décio Cagnine, who produces organic food on his property, beyond providing advice to other farmers in the region. From this context, public policies are superimposed for discussion, which not only support these farmers, but also regulate the insertion of organic and agroecological practices among the smallholders of this region.
\end{abstract}

Keywords: Cooperative of the Organic and Agroecological Producers of the Southwest of Paraná Coopervereda; Agrarian History; Memoirs; Small properties; Southwest of Paraná.

\title{
1. Introdução
}

A região Sudoeste do Paraná enquanto espaço geográfico e político existe a pelo menos 100 anos, desde o fim da Guerra do Contestado, quando ficam estabelecidas as fronteiras atuais entre o Paraná e Santa Catarina. Este espaço, que é entendido aqui como região, ${ }^{3}$ possui em seus processos de ocupação algumas peculiaridades. A mais significativa delas são, sem dúvida, os levantes sociais ocorridos em outubro de 1957, que ficaram conhecidos como Revolta dos Colonos ou Posseiros.

O movimento de 1957 aconteceu entre colonos - em sua grande maioria, migrantes do Rio Grande do Sul, Santa Catarina e de outras regiões do Paraná - e companhias colonizadoras que se diziam detentoras das terras ocupadas pelos colonos. $\mathrm{O}$ incentivo à migração para esta região acontece com a criação da Colônia Agrícola Nacional General Osório - CANGO. Esta Colônia agrícola é estabelecida por Getúlio Vargas junto ao programa

\footnotetext{
${ }^{3} \mathrm{O}$ conceito de região é considerado a partir da definição de Tarcísio Vanderlinde, que além de ressaltar sua diversidade e complexidade, destaca que sua definição esta imbricada "aos critérios adotados pelo IBGE", ao se referir a "um território de ação e controle". Neste sentido, tal conceito dialoga com a geografia não apenas em termos de localização, mas também no que se refere ao aspecto territorial, isso significa refletir suas acepções, tanto enquanto "unidade administrativa", quanto como espaço de relações políticas, econômicas e sociais. Entretanto, em relação às denominações constituídas por estados e municípios, poderíamos acrescentar as indicações de microrregião e mesorregião, sendo que a primeira apresenta-se como a divisão ou o agrupamento de determinado número de municípios limítrofes. O Sudoeste do Paraná é, portanto, uma mesorregião que possui três microrregiões, notadamente, Capanema, Francisco Beltrão e Pato Branco. Para maiores esclarecimentos verificar: VANDERLINDE, Tarcísio. Região. In: MOTTA, Márcia (org.). Dicionário da terra. Rio de Janeiro: Civilização Brasileira, 2005. p. 391, 392, 393.
} 
político governamental denominado "Marcha para Oeste". Com o objetivo de ocupar novas fronteiras agrícolas a Oeste do Brasil, incentiva a migração para regiões pouco exploradas, como o caso do Sudoeste paranaense.

Porém, esses colonos, ao chegarem à região, encontram um contexto peculiar de indefinição jurídica da terra. Um problema que vinha desde o início do século XX e que envolvia o estado do Paraná, União e interesses particulares, impedia a titulação das terras. Na década de 40 e 50, essa indefinição que envolvia as Glebas Missões e Chopim, em uma extensão territorial de $4.257 .100 .000 \mathrm{~m}^{2}$ para a primeira gleba e $715.080 .142 \mathrm{~m}^{2}$ para a segunda, vai ganhar novos e significativos capítulos. Isso porque é eleito governador do estado do Paraná Moysés Lupion, que em vista de seus interesses particulares ou de seu grupo, o "Grupo Lupion”, decide “colonizar” as terras em questão cobrando-as dos colonos.

É a partir dessa conjuntura de indefinição jurídica e também de instabilidade social, em razão das ações das companhias colonizadoras através de seus jagunços, que os colonos decidem organizar levantes sociais para reivindicar o que lhes era de direito, a terra, os quais ocorrem em outubro de 1957 nos principais aglomerados urbanos da época, Francisco Beltrão, Pato Branco, Santo Antônio do Sudoeste e Capanema.

Após o sucesso dos colonos em seus levantes e a regularização da posse da terra nas décadas de 1960 e 70, boa parte da memória pública que é constituída sobre essa região e esses eventos sociais, distingue esse espaço por ter uma caracterização fundiária singular, sobretudo, ao caracterizar uma estrutura fundiária de pequenas propriedades, que seria fruto dos levantes sociais de 1957.

Isso também pode se verificar em algumas historiografias que se debruçaram sobre essa região e seus levantes. Desta maneira, minhas pesquisas procuram questionar a estrutura agrária e fundiária da região, pautando-se em hipóteses que sinalizam uma significativa transformação da estrutura fundiária desse espaço na contemporaneidade, sobretudo, em relação ao aumento das grandes propriedades e latifúndios, a partir do agronegócio e a retração no número de pequenas e médias propriedades agrícolas.

Destarte, nos primeiros levantamentos constatou-se a significativa atuação, tanto, de cooperativas agrícolas e de crédito, que incentivam a produção de monoculturas, quanto, de centros de apoio e promoção da produção orgânica e agroecológica, como a Cooperativa dos Produtores Orgânicos e Agroecológicos do Sudoeste do Paraná - Coopervereda.

Deste modo, utilizando-se da metodologia oral, este trabalho expõe para debate as formas de atuação desta Cooperativa no município de Verê, com atenção especial para seu trabalho junto aos agricultores da região. Para tanto, será utilizada uma entrevista realizada 
com os agricultores Décio Cagnine e Izolete Bornhofen Cagnine, que produzem em sua propriedade alimentos orgânicos, além de prestar assessoria a outros agricultores da região. A partir deste contexto, se sobrepõe para discussão as políticas públicas, que não só dão sustentação a tais agricultores, como também regram a inserção de práticas orgânicas e agroecológicas entre os pequenos proprietários desta região.

\section{Camponeses e campesinato: algumas considerações}

Antes de conhecermos as trajetórias de vida de Décio e Izolete, cabe introduzirmos algumas questões em torno da definição de camponês ou de campesinato, sobretudo pensando em sua aplicabilidade na região aqui estudada e nos personagens aqui privilegiados. Será que é possível considerarmos os mesmos camponeses?

Pois bem, para respondermos ou simplesmente pensarmos essa questão serão introduzidas algumas discussões em torno do mesmo. Nessa seara, inicialmente expõe-se a atribuição de Vladimir Ilitch Lênin em seu trabalho $O$ desenvolvimento do Capitalismo na Rússia: o processo de formação do mercado interno para a grande indústria. Lênin procura pensar as características fundamentais desse processo de desintegração do campesinato tentando definir sua importância. Para tanto, se utiliza dos dados estatísticos, por estabelecimento, dos Zemstvos. São analisados dados de sete províncias.

Lênin Destaca inicialmente que o campesinato russo é regrado por uma economia mercantil que o subordina ao mercado. Soma-se a isso a proletarização da imensa maioria dos camponeses, enquanto o restante consegue inserir-se no sistema pequeno burguês. Todas as distinções no interior do campesinato conduzem a sua desintegração ou decomposição, o que desencadeia novos tipos de população rural, conforme evidencia:

O conjunto das contradições existentes no interior do campesinato constitui o que denominamos desintegração do campesinato. Empregando a palavra "desintegração", os próprios camponeses fornecem uma definição extremamente precisa e relevante desse processo, que redunda na destruição radical do antigo campesinato patriarcal e na criação de novos tipos de população rural (LÊNIN, 1985, p. 113).

É interessante pensarmos quais são essas novas populações rurais não camponesas, ou seja, para Lênin o rural não deixa de existir, o que ocorre é a desintegração do antigo campesinato que passa a ser composto basicamente por duas categorias: o primeiro é o campesinato rico com cultivadores independentes, além deste, também temos os proprietários 
de estabelecimentos industriais e comerciais. Enquanto o segundo é o proletariado rural: são aqueles camponeses que possuem um lote comunitário, incluindo-se o camponês pobre semterra. São, portanto, diaristas, assalariados agrícolas, peões, etc.

Lênin menciona ainda o camponês médio, que sobrevive com dificuldades e está suscetível a crises do sistema agrícola. Alguns conseguem subir ao grupo superior, mas a grande maioria acaba caindo ao grupo do campesinato pobre. Nesse sentido, para o autor, esse processo de desintegração cria um mercado interno para o capitalismo. O camponês pobre produz menos e precisa comprar mais, enquanto o rico compra mais por dispor de mais capital.

Dessa maneira, no entendimento de Lênin, existe uma tendência à desintegração do campesinato que o divide basicamente em dois grupos dentro do sistema capitalista de produção. Mas, até que ponto essas considerações de Lênin ainda nos podem servir para compreendermos a realidade contemporânea? Será que o campesinato está fadado ao desaparecimento ou recria-se de acordo com as condições que lhe são apresentadas?

Outro autor que menciona pressupostos em relação ao desaparecimento do campesinato é Karl Kautsky, que percebe a evolução da indústria enquanto fator preponderante para a modificação da produção rural. Nessa linha argumentativa salienta que o camponês da Idade Média não dependia do mercado, descreve o quadro deste camponês em contrapartida com a sua dissolução com a revolução econômica provocada pelas relações capitalistas na agricultura.

Salienta assim, o aparecimento da indústria e do comércio nas cidades, enquanto, por outro lado, desaparece a indústria do camponês que produz para si mesmo: "a dissolução da indústria do camponês que produzia para si mesmo já começará na Idade Média, quando apareceu a pequena indústria urbana. Mas essa produção apenas lentamente penetrava no meio rural" (KAUTSKY, 1980, p. 31). A dissolução da indústria doméstica acontece à medida que se aumenta a necessidade de dinheiro entre os camponeses. Junto a isso também aumenta as forças que exploram esses camponeses.

Kautsky entende que o camponês vai aos poucos se destituindo de suas relações agrícolas até o ponto que não suporta mais essas relações e consequentemente se desintegra das mesmas. Uma consequência desse processo é a própria desintegração da prole, que abandona o espaço rural.

Mas à medida que progride a evolução econômica e política, as necessidades pecuniárias do pequeno camponês aumentam. O Estado e a comuna cada vez mais avançam sobre sua bolsa. Quanto mais se vê compelido a ganhar dinheiro, tanto 
mais deve dedicar-se a um trabalho acessório, em detrimento de sua agricultura (KAUTSKY, 1980, p. 188).

Isso significa que, para Kautsky, o desenvolvimento industrial estabelece uma transformação cada vez mais estreita entre a pequena propriedade territorial e o proletário sem posses. Que se aproximam cada vez mais. Ou seja, enxerga uma tendência do pequeno camponês em se tornar proletário sem posses.

É possível notar em que medida Lênin e Kautsky elaboram suas considerações a partir de um posicionamento que percebia o desaparecimento do campesinato dentro do sistema capitalista de produção. Mas, vamos pensar essas relações em um contexto mais contemporâneo ou de uma realidade mais próxima. Ariovaldo Umbelino de Oliveira em seu trabalho: Modo capitalista de produção, agricultura e Reforma Agrária, nos expõe uma nova perspectiva interpretativa para as relações estabelecidas pelo campesinato na contemporaneidade.

De acordo com Oliveira - ao contrário da tese exposta por Lênin e Kautsky - o campesinato não só sobrevive dentro do capitalismo, como também recria-se para sustentarse. Salienta que "a permanência, como também o aumento do campesinato na agricultura" acontece enquanto fruto do próprio "processo de desenvolvimento do modo capitalista de produção", isso significa que, tanto o campesinato quanto o latifúndio devem ser vistos e entendidos enquanto processos intrínsecos do desenvolvimento do capitalismo na agricultura e não fora de tais relações (OLIVEIRA, 2007, p. 11).

Oliveira nos sugere ainda que:

O campesinato deve, pois, ser entendido como classe social que ele é. Deve ser estudado como um trabalhador criado pela expansão capitalista, um trabalhador que quer entrar na terra. $\mathrm{O}$ camponês deve ser visto como um trabalhador que, mesmo expulso da terra, com frequência a ela retorna, ainda que para isso tenha que (e)migrar. Dessa forma, ele retorna à terra mesmo que distante de sua região de origem. É por isso que boa parte da história do campesinato sob o capitalismo é uma história de (e)migrações (OLIVEIRA, 2007, p. 11).

Por ser fruto da expansão do capitalismo, o capital pode subordinar esse camponês aos modelos de produção propostos pelo mercado - seja ele de terras ou simplesmente de produtos agrícolas - e não só nesse sentido, como também sujeitar o campesinato ao trabalho que deve desenvolver na terra. Isso faz com que a pequena produção camponesa seja uma atividade desenvolvida e sustentada pelo capital.

Sob essa conjuntura, o trabalho de Oliveira nos dá um panorama e algumas respostas para uma das questões colocadas anteriormente, para Oliveira, o campesinato recria-se dentro 
da lógica de produção e reprodução das relações econômicas e sociais expostas pelo capitalismo, mas, e os entrevistados privilegiados nesse trabalho, são camponeses? Sob que lógica criam e recriam suas relações no espaço rural? Evidentemente só poderemos responder isso ao final do texto, mas, são questões que perpassam nossa discussão.

Nessa linha argumentativa podemos ponderar as considerações de Teodor Shanin, que procura pensar de que maneira esse conceito é construído e desconstruído a partir de leituras marxistas. Shanin salienta que a "heterogeneidade dos camponeses é indubitável" ao enfatizar que não conseguimos compreender essa definição sem entendermos "sua estrutura societária mais geral" (SHANIN, 2005, p. 2). Entretanto, para o autor, quando nos propomos fazer esse tipo de discussão, ou seja, compreender o campesinato a partir de suas estruturas, o camponês acaba sendo generalizado e não pensado a partir de suas diferentes heterogeneidades.

Essas generalizações estão constituídas a partir de categorias de características, assim, embora não seja o objetivo de Shanin deixar explicita uma hierarquia de tais categorias, ele procura deixar claro que:

\begin{abstract}
A especificidade do camponês reflete a interdependência entre os elementos básicos mencionados e não pode ser pura e simplesmente reduzida a qualquer um deles. Ao mesmo tempo, o cerne de suas características determinantes parece repousar na natureza e na dinâmica do estabelecimento rural familiar, enquanto unidade básica de produção e meio de vida social. Consequentemente, a própria existência do camponês, como uma entidade social específica, depende da presença de estabelecimentos rural familiares como a unidade básica da economia e da sociedade. O camponês deve ser compreendido, portanto, através da investigação das características do estabelecimento rural familiar camponês, tanto internas quanto externas, isto é, suas especificidades reações e interações com o contexto social mais amplo (SHANIN, 2005, p. 2).
\end{abstract}

No entendimento de Shanin, devemos perceber o campesinato a partir na natureza e dinâmica do estabelecimento familiar. É evidente que tal estabelecimento não está isolado, mas sim, inserido em relações econômicas e sociais internas e externas, fruto das relações expostas pelo próprio capitalismo.

Quem também manifesta considerações acerca do campesinato é José de Souza Martins. Para esse autor o campesinato também recria-se a partir das relações políticas, econômicas e sociais expostas pelo capitalismo. Nesse sentido, Martins demonstra ao longo de seu trabalho de que maneira o campesinato se estabelece enquanto luta pelo acesso a terra no Brasil:

Particularmente a partir dos anos 1950, camponeses de várias regiões do país começaram a manifestar uma vontade política própria, rebelando-se de vários modos contra seus opressores, quebrando velhas cadeias, levando proprietários de terras aos 
tribunais para exigir o reparo de uma injustiça ou o pagamento de uma indenização; exigindo do Estado uma política de reforma agrária; resistindo de vários modos a expulsão e despejos (MARTINS, 1995, p. 10).

Ocorre, assim, um fortalecimento da presença política nas lutas camponesas. Para Martins, o PCB, as Ligas Camponesas e alguns setores da Igreja disputaram a hegemonia na organização dos trabalhadores rurais, o que evidentemente não significa que não possam ter surgido movimentos sociais no campo sem a presença dessas entidades. Porém, em grande medida, o que o autor nos faz olhar é a possibilidade de transformação que o campesinato percebe e almeja. O passado aparece enquanto aprendizado junto à noção de expropriação e de reforma agrária. Tais categorias são apresentadas ao horizonte do trabalhador rural brasileiro, o qual passa a perceber que, sem uma luta contra a opressão da classe agrária dominante, sua condição não se alteraria e que a reforma agrária seria um viés para a superação das relações de poder imposta ao meio rural brasileiro.

\section{Narrativas sobre o trabalho rural com alimentos orgânicos}

Serão expostas a seguir algumas vivências agrícolas do casal de agricultores Décio Cagnine e Izolete Bornhofen Cagnine, que produzem em sua pequena propriedade agrícola, no município de Verê, alimentos orgânicos. Certamente não caberia encerarmos essa empreitada com narrativas de agricultores possuidores de grandes e médias propriedades agrícolas, que produzem monoculturas para o mercado externo - vinculados ao agronegócio. Não por tais experiências não terem validade acadêmica, pelo contrário, acredito que seja exatamente esse o caminho a ser percorrido para aprofundarmos e conhecermos, sob que bases o agronegócio brasileiro está sustentado e o que lhe dá credibilidade na economia mundial.

Mas sim, para pensarmos em que medida o que resta da caracterização fundiária de pequenas propriedades dessa região, pode ser apropriada para práticas agrícolas que de fato produz alimentos saudáveis à mesa dos brasileiros. Conforme evidenciado, a entrevista foi realizada com o senhor Décio Cagnine e sua esposa Izolete Bornhofen Cagnine, na ensolarada tarde de sábado, dia 21 de maio de 2018, o local escolhido foi à residência dos entrevistados na comunidade rural de Vila Colonial, município de Verê-Pr.

Antes de maiores considerações acerca das experiências e vivências de Décio e Izolete é importante salientar que muitos dos aspectos agrícolas expostos pelos entrevistados dialogam com as informações apresentados por Jhony Luchmann em relação à atuação do 
Centro de Apoio e Promoção da Agroecologia - Capa. ${ }^{4}$ A correspondência existente entre o Capa e a propriedade agrícola de Décio e Izolete é muito significativa, primeiro porque o Capa é um dos principais meios de apoio aos agricultores que produzem alimentos orgânicos e agroecológicos no Sudoeste do Paraná, em especial no município de Verê, local onde está localizado um dos escritórios do órgão.

Segundo porque, o próprio Décio - isso eu somente fui descobrir após ter iniciado a entrevista - trabalha no Capa de Verê, prestando assessoria aos agricultores do próprio município e dos demais municípios da região, em termos de produção agrícola orgânica ou agroecológica. Ou seja, a significativa experiência de Décio com a produção orgânica, desde o início dos anos 2000, fez com que ele fosse trabalhar no Capa de Verê.

Mas, o que me levou até Décio e Izolete não foi o contato com o Capa, mas sim, o evidente sucesso que a Cooperativa dos Produtores Orgânicos e Agroecológicos do Sudoeste do Paraná - Coopervereda, tem nessa região. Deste modo, coincidência ou não, a Coopervereda está situada no município de Verê e, no momento, é a principal cooperativa de produtos orgânicos e agroecológicos da região. Assim, a partir do contato estabelecido com funcionários dessa cooperativa, me foi indicado o nome de Décio e Izolete como excelentes para narrar suas vivências com a produção de produtos orgânicos.

As narrativas de Jonhy e Décio possuem pontos de interconexão, mas ambas têm suas próprias peculiaridades. No momento da entrevista Décio estava com 54 anos, nasceu na propriedade onde reside, a qual pertencia aos seus pais. Os pais de Décio tiveram uma trajetória muito similar a muitos agricultores que migram para o Sudoeste do Paraná, no contexto de instabilidade social vivido em relação à posse da terra. Agricultores, migrantes de Cacique Doble-RS, possuíam uma pequena propriedade no Rio Grande do Sul e decidem migrar para o Paraná no ano de 1954, em busca de terras mais férteis e menos montanhosas. Nesse sentido, o entrevistado salienta que seus pais tiveram 14 filhos, destes, 12 ainda estão vivos e dois já faleceram.

Sob esta perspectiva, Décio destaca de que maneira a área inicial de seu pai foi dividida entre os irmãos, fazendo com que ele ficasse com os três alqueires e meio onde reside hoje com sua esposa e dois filhos: "a área era de 50 hectares e aí ele foi, foram dividindo, dois alqueires pra um, dois alqueires pra outro, sobraram três alqueires e meio aqui

\footnotetext{
${ }^{4}$ Indica-se isso, pois, realizei no ano de 2017 uma entrevista com o então diretor do Capa de Verê-Pr Jhony Luchmann.
} 
para mim, daí estou com a propriedade e com o terreno ainda" (CAGNINE, Décio, 2018, p. 2).

Conforme evidenciamos, Décio tem toda uma trajetória ligada a terra, já que seus país eram os detentores da propriedade que possui hoje, evidentemente não tem todo o terreno que seus pais tinham, mas frisou ao longo da entrevista que sua família consegue tirar grande parte do sustento da propriedade. Izolete também tem um percurso similar ao de Décio, seus pais residem em uma propriedade agrícola significativamente próxima da dos entrevistados, também não possuem muita terra, de acordo com Izolete a propriedade de seu pai têm apenas cinco alqueires e meio.

Após conhecer um pouco das trajetórias de Décio e Izolete ligadas à agricultura, os interrogo em relação às culturas agrícolas que ganham mais evidência em sua propriedade, deste modo, Décio enfatizou:

As minhas atividades principais aqui é hortaliças e frutas orgânicas, todas elas orgânicas. No começo a gente começou, bem no começo há uns 25 anos atrás eu tinha fruticultura convencional e aí depois, uns praticamente uns 16, 17 anos atrás, aqueles cultivares que daquela época eram os bons passaram a não ser mais, então uma parte começou a adoecer e aí a gente retirou, aí a gente não trabalhou mais com fruticultura e aí nesse intermediário a gente começou a trabalhar com hortaliças, mas já começando a trabalhar com hortaliças orgânicas (CAGNINE, Décio, 2018, p. 2, 3).

O primeiro ponto que podemos destacar sobre as culturas agrícolas da propriedade de Décio e Izolete é em relação às frutas e hortaliças, já que são essas que se destacam e ganham significativa atenção no dia a dia de trabalho de Décio e sua família. Deste modo, é possível notar que o entrevistado demonstra logo de início ter todo um conhecimento na área de produção orgânica. Consegui perceber que isso se deve em grande medida por dois fatores: primeiro pela experiência de Décio e Izolete nesse modelo de agricultura, há mais de 20 anos trabalhando com fruticultura e pelo menos 16 anos com frutas e hortaliças orgânicas; o segundo fator, não revelado nesse momento, se deve a formação de Décio, que possui curso Técnico Florestal, além de outras especializações em horticultura orgânica.

Nosso entrevistado não é um simples agricultor que aventura-se na produção de produtos orgânicos e agroecológicos, conforme fica claro no desenvolvimento de sua narrativa, possui larga experiência nesse meio agrícola com um vasto conhecimento técnico, que o faz inclusive, prestar assessoria técnica sobre o tema a outros agricultores da região.

Mas, todo esse conhecimento que Décio expõe, em relação à área que atua foi duramente conquistado, tendo como um dos principais obstáculos o preconceito e o pouco 
crédito que os agricultores da região davam a agricultura orgânica, em fins da década de 1990 e início dos anos 2000. De acordo com que o próprio entrevistado evidencia:

[...] então se a gente volta no tempo lá quando eu comecei a produção orgânica era muito tímida, quase ninguém. Tanto é que eles tachavam nós que trabalhava no Capa como uns loco: "aqueles loco do Capa querendo, imagine querendo planta tomate sem usa veneno!". "Imagine aqueles cara, aqueles loco lá planta alface e não usar veneno" e nós quietos no nosso canto (CAGNINE, Décio, 2018, p. 3).

A inserção de um modelo de agricultura diferente, daqueles vivenciados pelos agricultores da região, causou um claro estranhamento e se tornou até motivo de chacota, já que a grande maioria dos agricultores não acreditava ser possível o desenvolvimento de culturas agrícolas sem o uso de veneno, ainda mais uma cultura vil, como o tomate ou a alface. Outro preconceito que recaía sobre os agricultores era em relação ao pouco retorno financeiro que a produção orgânica traria, já que a região não tem grandes e médias cidades, além do mais, a produção agrícola convencional naquele período, apesar de não ter a segurança econômica que tem hoje, ainda era vista como mais confiável do que a produção de produtos orgânicos.

É sobre todas essas particularidades que Décio e sua família, bem como os demais agricultores da região, que optam por esse modelo de agricultura, precisam transpor para inserir-se em um modelo de produção orgânica que lhes desse retorno financeiro. Assim, Décio enfatiza que a passagem da agricultura convencional para a orgânica não foi fácil, principalmente em razão do pouco conhecimento que ele e os demais entusiastas da ideia tinham sobre o assunto no Sudoeste do Paraná.

Décio menciona que, no início, como sua propriedade está localizada próximo da sede urbana do município de Verê, ele juntamente com outros técnicos do Capa e demais interessados nas culturas agrícolas orgânicas, optavam por fazer experimentos em sua propriedade, já que era a de mais fácil acesso. Isso fez com que Décio sentisse as dificuldades dessa transição de forma muito mais impactante, já que a maioria dos experimentos e consequentemente erros aconteciam em sua propriedade agrícola.

Sobre as dificuldades iniciais, um dos pontos ressaltados pelo entrevistado foi à questão das dimensões das estufas:

[...] já no começo já comecemos a botar estufa plástica, que aquela época estufa plástica na região não tinha e aí a gente olhava muito pros aviário de frango, que naquela época lá era 10 por 50 [metros] o padrão, nós achamos, vamos fazer, vamos começar a montar estufa de 10 por 50, bem grande sabe, “nossa imagina!". Mas não 
deu nada certo por que era muito grande e nos primeiros ventos que dava levava embora (CAGNINE, Décio, 2018, p. 4).

Como não tinha referências nesse modelo de produção, às primeiras estufas plásticas construídas na propriedade de Décio tiveram que ser reconstruídas, muito disso se deve ao vento que arrancava o plástico e fazia com que todo o esforço de Décio e sua família "fossem pelos ares" literalmente. Sobre esse contexto, Izolete arrancou gargalhadas de todos os presentes na entrevista quando enfatizou que reconstruíam a estufa e "Daí toda vez era o vento levou!". Ou seja, o modelo de estufa que estavam utilizando, 10 X 50, não suportava a força do vento, o que fazia com que perdessem todo o investimento e trabalho empregado na construção.

Décio destacou que não foi somente o vento um entrave em seus primeiros anos na produção de produtos orgânicos. A estufa nas dimensões indicadas pelos entrevistados, isto é, de 10 metros de largura por 50 de comprimento, não permitia que eles tivessem grande rotação de culturas, além de dificultar o controle de pragas e doenças. Assim, esse modelo de estufa precisou ser rapidamente abandonado, sendo diminuindo ao longo dos anos, chegando atualmente numa dimensão considerada ideal pelo entrevistado, que é de 5 metros de largura por 21 de comprimento.

Nessas dimensões, de acordo com Décio, se torna mais fácil o controle de pragas e doenças, evitando a perda de toda a produção, além de serem mais resistentes às forças do vento.

Conforme evidenciamos, Décio e Izolete nos expõem interessantes narrativas sobre a inserção da família na produção agrícola orgânica. Mas, evidentemente que a assessoria do Capa não foi suficiente para o avanço da produção orgânica no município de Verê e na região. Um dos fatores que influenciou o desenvolvimento da produção orgânica em Verê foi a Associação dos Produtores Agroecológicos - Apav, que posteriormente se transformaria na atual Coopervereda, conforme menciona Décio:

Em 2001 foi criada a Apav, Associação dos Produtores Agroecológicos, Apav, associação enfim. E aí ela conseguiu lá, não sei como, isso raro no Paraná, só duas associações que conseguiram ter nota de venda e a Apav tinha. Mas a associação ela se restringe muito aos vários, digamos assim, questão de recursos, quando é uma cooperativa é muito mais fácil de conseguir recursos, quando é uma cooperativa ela têm os benefícios e têm os, você pode destinar sobras, enfim tem uma série de vantagens de ser cooperativa e a associação ela tava muito restrita, então pensou-se em formar uma cooperativa para ampliar mais, tanto é que ela é do Sudoeste do Paraná, então pega, temos sócios de vários municípios já e pra gente pensar em crescer mais, como cooperativa pensar em crescer mais e ficar dentro de uma, ficar mais legal [juridicamente] digamos assim. Foi criada, se não me engano, acho que 
em 2014, então, até ela agora que digamos assim ela tá começando a se estabilizar e começa a melhorar também (CAGNINE, Décio, 2018, p. 13).

Décio nos apresenta um panorama geral da atuação da Apav, desde 2001, data da sua criação, até 2014, quando é extinta para dar lugar a Coopervereda. É interessante notar as motivações que levam os agricultores a abandonar a associação e inserir-se no modelo cooperativista. De acordo com o entrevistado, isso se deve primeiro porque a associação estava muito restrita ao município de Verê, mesmo sendo uma das poucas associações do estado do Paraná que possuía nota de venda de seus produtos. Mas, além disso, menciona que o modelo cooperativista pode proporcionar uma série de vantagens aos sócios, como, por exemplo, a destinação de sobras financeiras.

Notamos em que medida subsiste perspectivas agrícolas distintas de cooperativismo na região estudada. Já que, existe uma forte presença de cooperativas de crédito e agrícolas a partir do modelo de produção agrícola agronegociante. Mas, isso não excluiu a possibilidade de que tenhamos cooperativas que trabalhem com um modelo de agricultura diferente, como a agricultura orgânica ou agroecológica. Afinal, apesar da grande expressão que o modelo cooperativista ganha junto ao agronegócio, não é somente a partir deste padrão que o mesmo pode apresentar-se.

Evidentemente que a inserção da Coopervereda na agricultura da região não chega nem próximo da de outras cooperativas como a Coasul, que tem mais de 7.000 associados. A Coopervereda tem em torno de 40 famílias, em sua maioria do município de Verê, apesar de possuir sócios nos municípios de Itapejara do Oeste, São Jorge do Oeste e Dois Vizinhos.

Deste modo, Décio salienta que nem todos os agricultores que fazem parte da cooperativa estão totalmente inseridos na produção de alimentos orgânicos, muitos ainda estão em processo de transição da agricultura convencional para a orgânica, isso significa que esses agricultores não produzem somente alimentos orgânicos em sua propriedade, mas também convencionais. Nesse sentido, tanto o Capa quanto a própria cooperativa, orientam uma transição aos produtores, ou seja, faz-se um plano de manejo da propriedade para que dentro de algum tempo ela seja totalmente orgânica.

Décio também esclareceu que esse processo de transição do convencional para o orgânico também influencia no processo de certificação, já que de acordo com o modelo de produção praticado na propriedade, totalmente orgânico ou parcialmente, muda-se também a certificação.

Sob esta perspectiva, questiono, na sequência da entrevista, a questão da assistência técnica institucional aos agricultores orgânicos, o que Décio destaca da seguinte maneira: 
Não! Emater [Instituto Paranaense de Assistência Técnica e Extensão Rural] não, acho que eles nem sabe onde eu moro! [alguns risos]. Não sei se sabem, mas enfim assim, não tem. O que a gente faz é assim, como a minha propriedade é uma propriedade assim que a gente faz muita pesquisa aqui, a gente faz parcerias com as universidades (CAGNINE, Décio, 2018, p. 15).

Notamos de que maneira Décio destaca a presença e influência de órgãos institucionais enquanto assistência aos agricultores da região, assim, é interessante observar que o entrevistado menciona a Emater, órgão que teoricamente deveria prestar assistência técnica e extensão rural aos agricultores da região, mas que, de acordo com o entrevistado, não oferece de forma satisfatória esses serviços. Décio chega inclusive a afirmar que acredita que os "eles", os funcionários da Emater, não sabem nem "onde" ele reside, tamanho o desinteresse que os mesmos têm por políticas agrícolas nesse sentido.

Evidentemente que Décio elabora esse discurso, não só enquanto agricultor orgânico, mas também a partir da posição que ocupa no Capa, isto é, certamente o fato de fazer parte de um órgão que assessora agricultores orgânicos e agroecológicos, o faz elaborar uma narrativa crítica quanto as políticas públicas de assistência a produção agrícola orgânica. Desta forma, sua subjetividade narrativa está implícita nas suas vivências e é explicitada na construção do discurso narrativo, que o leva a ver com desdenho alguns órgãos governamentais, nesse caso, a Emater.

Mas, uma questão que merece atenção é em relação às parcerias que Décio faz com universidades. No dia da entrevista, mencionou "uma parceria com a UTF[PR] de Pato Branco", mas especificamente com um professor doutor na área de fruticultura. Assim, enfatizou que em mais de uma oportunidade desenvolveram experimentos com tomate e morango, práticas que não só desenvolvem pesquisas sobre o assunto, como também fornecem mais conhecimento sobre o assunto a Décio e sua família.

Outro ponto interessante da narrativa de Décio e Izolete é quando tratam da comercialização da produção agrícola. Sublinham que boa parte é vendida na própria propriedade, já que muitas pessoas do município já sabem que Décio e Izolete produzem alimentos orgânicos, assim, sempre que a notícia se espalha sobre a colheita de verduras, tomate ou algum outro alimento, com frequência aparecem compradores na própria residência. A título de exemplo, no dia que estava sendo gravada a entrevista, chegou à propriedade um sujeito com a intenção de comprar alface, o qual foi prontamente atendido por Izolete. 
Além da produção comercializada na propriedade, grande parte é entregue na cooperativa Coopervereda, que vende uma pequena parcela no mercadinho que possui na cidade de Verê, enquanto o restante é comercializado por intermédio de políticas públicas. De acordo com o que menciona Décio, quando interpelado sobre a venda de alimentos a partir de políticas públicas:

\begin{abstract}
Sim, tudo é política pública! Toda a cooperativa ela, assim, o mercado institucional na verdade é PAA, que é Programa de Aquisição de Alimentos, que é um programa que é da Conab [Companhia Nacional de Abastecimento], onde o agricultor produz e entrega pra cooperativa, a cooperativa entrega pras entidades, pra Sesc Mesa Brasil, pras escolas, pras Creches, APAE, APMI, em fim, entrega, pega faz a nota de tudo que entrega no mês, manda pra Conab, a Conab ela soma isso, confere a documentação e libera o dinheiro no banco pra cooperativa, a cooperativa pega o dinheiro e paga os agricultor, quer dizer é um dinheiro que, o produtor produz aqui, mas o dinheiro vem de fora e ele fica no município, essa é uma política pública (CAGNINE, Décio, 2018, p. 16, 17).
\end{abstract}

Décio nos esclarece de que maneira uma política pública, no caso, o Programa de Aquisição de Alimentos - PAA, da Companhia Nacional de Abastecimento - Conab, beneficia a cooperativa e os agricultores cooperados. Menciona assim, que toda a produção que a cooperativa recebe é direcionada para o mercado institucional, com exceção evidentemente da parcela que é comercializada no mercadinho, afora isso, a produção está vinculada aos programas públicos, que nas palavras do entrevistado, trazem inúmeras vantagens ao município, tanto financeiras quanto alimentícias. Primeiro porque são alimentos saudáveis e livres de agrotóxicos que são oferecidos para escolas, Creches, APAE e APMI(s) dos municípios da região, segundo porque, o governo paga a cooperativa e a cooperativa repassa o valor aos agricultores, o que significa uma injeção financeira na economia do município e da região.

Mas, não é somente essa política pública que sustenta os agricultores e a cooperativa. Décio menciona também o Programa Nacional de Alimentação Escolar - PNAE, cujos recursos são oriundos do governo estadual e federal em parceira. $\mathrm{O}$ entrevistado sinaliza que esse programa: "é alimentação pras escolas estaduais, então também, a cooperativa acessa, tanto é que ela vai entregar no município do Verê e no município de São João esse ano" (CAGNINE, Décio, 2018, p. 17). Ou seja, a cooperativa já firmou contratos, com os municípios de Verê e São João, para fornecer alimentos orgânicos para as escolas estaduais destes municípios no ano de 2018.

Além das vendas por intermédio de políticas púbicas a nível federal e estadual, Décio também expressa as vendas que são realizadas diretamente com a administração municipal de 
Verê "tem a merenda municipal, que é pros colégios municipais, então a prefeitura ela demanda tantos pés de alface, ela demanda as hortaliças, passa pra cooperativa, a cooperativa faz” (CAGNINE, Décio, 2018, p. 17). Décio indica que nessas transações a nível municipal a cooperativa consegue negociar o preço diretamente com a prefeitura, o que não só beneficia a cooperativa, mas os agricultores também.

A partir desse cenário, é interessante notar em que medida Décio e Izolete valorizam a atuação da Coopervereda ao longo de suas narrativas, demonstrando abertamente, não só uma defesa da cooperativa, mas daquilo que ela representa aos agricultores da região que produzem alimentos orgânicos. Suas narrativas constituem-se enquanto diálogo, primeiro com a realidade que vivenciam em suas práticas diárias enquanto agricultores, segundo na atuação que ambos tem, no Capa, no caso de Décio, e na Coopervereda, no caso de Izolete, ao considerar que exaltou em sua narrativa que trabalha alguns dias da semana para a agroindústria da cooperativa.

É nesse ponto que as narrativas expõem-se enquanto diálogo, evidentemente os entrevistados não elaboram seus discursos enquanto meros agricultores, tampouco apenas enquanto representantes de entidades que defendem a produção orgânica e agroecológica. Mas sim, nesse ínterim, que os constituem tanto enquanto agricultores produtores de alimentos orgânicos como também enquanto defensores desse modelo de agricultura, que, há tanto, tempo constitui suas vivências.

Um dos itens que me chamou a atenção ao longo da narrativa de Décio, talvez por eu não conhecer essa realidade com tamanha clareza quanto os meus entrevistados, foi à questão da retração das políticas públicas que auxiliam a venda da produção orgânica dos agricultores, os famosos PAAs. Conforme menciona Décio, ao se referir à questão política brasileira e de que forma isso impacta nas políticas públicas voltadas a agricultura familiar:

Eu vejo assim que o agronegócio ele tá, ele tá tão presente, ele tá tão vivo nos comandantes lá de cima que dificilmente a gente vai conseguir reverter isso, então, o que eu penso assim é que se a gente conseguisse pelo menos resistir a esse pessoal, porque assim, não tem interesse em ter agricultura orgânica, não tem pro governo, pros governantes, não tem interesse. Pra eles o que interessa é agronegócio, é exporta, é isso. Assim, se tu for ver lá no Congresso aqueles que fazem as leis lá, são 10, 15 deputados lá da agricultura familiar que defendem os pequenos, tem uns 300 mais ou menos do agronegócio e tem uns 100, 150 empresários. Como que eles vão aprovar leis, direcionar as coisas pro pequeno agricultor!? Eles nem enxergam a gente, eles nem olham pra nós! Então assim, e tem outra, quando tem algum que quer puxar pro pequeno, os caras que bancaram eles lá, os cara do agronegócio eles vão lá e vão dizer assim: "cara, eu te elegi pra você fazer as leis pra me ajudar e não pra querer". Essa questão dos PAAs [Programa de Aquisição de Alimentos], se vocês entendem um pouco como que é? O que aconteceu com os PAA, aquele que prenderam os caras na região, no Paraná e [...]. Porque tava crescendo demais, tava 
indo demais bem esse troco, sabe, o agricultor pequeno nunca ganhou tanto dinheiro e sabe ele tava produzindo alimento, ganhando dinheiro, entregando e pegando dinheiro. Mas o que aconteceu, começou a mexer no bolso dos, da BUNGE, dessas grandes empresas que eles entregavam esses produtos, entendeu!? Aí, "opa cara, olha vamos parar com esse troco, vamos fazer alguma coisa, não vamos matar os caras, mas vamos, vocês ficam lá plantando o pouquinho de vocês, mas vocês tão tirando o nosso mercado". E vai acontecer assim sempre, vocês podem ter certeza, o interesse é maior (CAGNINE, Décio, 2018, p. 22, 23).

O primeiro ponto que evidenciamos é uma severa crítica às políticas desenvolvidas pelo governo federal, sobretudo a partir do agronegócio, que de acordo com Décio, apresentase enquanto expressão da agricultura brasileira, não havendo espaço para políticas que beneficiam o modelo de agricultura desenvolvido por ele e sua família. Nesse contexto, narra que existem poucos deputados que defendem a agricultura familiar, talvez 10 ou 15, enquanto o restante "nem enxergam a gente, eles nem olham pra nós!", referindo-se a bancada empresarial e do agronegócio que domina a cena política no Congresso Nacional.

Destarte, nesse ponto Décio direciona suas considerações para a questão da redução do PAAs, ao salientar que isso é fruto dessa conjuntura. Em sua visão, isso somente acontece porque esse programa começa a ganhar notoriedade e beneficiar um significativo número de pequenos agricultores, assim, evidencia que o sucesso alcançado trazia a contrapeso a diminuição das vendas de grandes empresas como a BUNGE, o que faz com que sejam tomadas atitudes, jurídicas no caso, para que os inúmeros programas de PAAs voltem ao patamar anterior e não "prejudique" tais multinacionais. ${ }^{5}$

Não entramos nesse momento no mérito da legitimidade da operação sinalizada pelo entrevistado, que causou a retração de políticas públicas para pequenos e médios agricultores. Mas evidenciamos em que medida, na trajetória histórica de nosso país, a impunidade teve marca registrada, verificando-se na contemporaneidade ações que visam claramente desmobilizar projetos, o que não se verificou ao longo do tempo e tampouco se verifica quando se mudam os atores sociais.

\footnotetext{
${ }^{5}$ A operação que Décio refere-se neste ponto é a Agro-Fantasma, deflagrada entre "2009 e 2013, com o objetivo de investigar supostos desvios no Programa de Aquisição de Alimentos (PAA), vinculado ao programa Fome Zero, e resultou em vários processos judiciais e na prisão infundada de agricultores de todo o estado. As prisões foram decretadas pelo juiz federal Sérgio Moro, em Curitiba". Na ocasião, "produtores rurais foram acusados de crimes de falsificação de documento público, falsidade ideológica, estelionato e associação criminosa. Além das associações e cooperativas de agricultores individuais, a Agro-Fantasma indiciou funcionários da Companhia Nacional de Abastecimento (Conab) por peculato e prevaricação". Essa operação contribuiu para a criminalização não só dos agricultores acusados, mas também de todo o Programa de Aquisição de Alimentos. Também é preciso salientar que no estado do Paraná todos os acusados foram absolvidos. Para maiores esclarecimentos ver: <https://terradedireitos.org.br/noticias/noticias/agricultores-sao-inocentados-de-acusacaode-desvios-no-programa-de-aquisicao-de-alimentos/22636> Acesso em 21 de novembro de 2018.
} 
Em vista disso, Décio expõe dados arrebatadores, que evidenciam em que medida tal ação retraiu o acesso de políticas públicas aos pequenos agricultores:

Tá loco! Em 2012, 2013 a cooperativa entregava pra mais de um milhão, era um, sabe, mas aí todo mundo, no Paraná tinha mais de 300 PAAs, todos os municípios tavam acessando, todo mundo tava ganhando dinheiro e aí deu aquele troco lá que, acharam que tinham roubado, depois não acharam nada, tá, arquivaram. Mas o que aconteceu, agora todo mundo tá receoso de fazer PAA porque pode ser que, então hoje no Paraná deve ter o que 20, 30 PAA funcionando, a cooperativa tem dois, mas assim, tem 20, 30 PAA e assim bem pequenino, o recurso cortaram, 95\% dos recursos que tava aí (CAGNINE, Décio, 2018, p. 23).

As ponderações de Décio são muito significativas e aparecem em tom e denúncia, ao demonstrar de que maneira o judiciário brasileiro pode atuar com a intenção de desmobilizar projetos, nesse caso, em benefício de grandes empresas, muitas delas multinacionais, em oposição, a retração de políticas públicas voltadas ao pequeno e médio agricultor. Décio analisa de forma comparativa, o período em que os recursos públicos estavam disponíveis, de forma significativa, para a aquisição de alimentos orgânicos, em contraste com a realidade presente, que faz com que a cooperativa tenha apenas dois PAAs, bem pequenos, como ele mesmo menciona.

Mas, não é necessário ser um especialista para entendermos em que medida na última década a produção e inserção dos produtos orgânicos no mercado alimentício teve um significativo crescimento. Por outro lado, também notamos em que medida, sobretudo após o golpe parlamentar de 2016, as políticas públicas voltadas às minorias, assim como recursos para saúde e educação, tiveram uma significativa redução. Já que o governo passa a atender com maior ênfase os interesses daqueles que o colocaram no poder, notadamente, o agronegócio, grandes empresários, multinacionais, enfim, todos os setores que representam a elite econômica brasileira.

Dada essa condição, não nos causa estranhamento o posicionamento crítico de Décio, e isso se deve, sobretudo, em razão da expectativa que tais políticas apresentam para a cooperativa e também para a família do entrevistado. Nessa mesma linha argumentativa, destaca de que maneira a atual conjuntura política brasileira expõe impactos na estrutura fundiária da região, com o avanço do agronegócio e a diminuição das pequenas e médias propriedades agrícolas:

Porque, o que tá acontecendo, o granjeiro tá na região, cada vez tão ficando maior, o pequeno tá ficando véio, não tá ficando os filhos na casa, pode [ver], vocês tiram essa conclusão vocês. Tá ficando só os velhos nas casas e os granjeiros tão ali esperando, pra eles se aposentar ou dá algum problema, tipo assim, daqui um pouco 
eu estou velho, os meus piá foram tudo pra cidade, eu vou vender a terra e vou comprar uma casa na cidade. Eles tão ali é isso que eles, o governo quer isso. Primeiro, que o agronegócio tome conta das áreas e que o filho do agricultor vá pra cidade, pra ele ser mandado pela agroindústria, pelos empresários, é isso, que é fácil, você tem mil empregado aqui e promete dar uns troquinhos pra manter ele vivo e dizer: "eu quero o meu voto aqui porque você tem emprego", muito mais fácil, é por isso que eu digo assim: "eu, se fosse eu trabalhar aqui na minha propriedade, eu consigo produzir alimentos pra alimentar mil pessoas todo dia", então porque o Brasil não pode ter, incentiva os agricultores pra ficar, pra eles, mas não é interesse, eles não têm interesse disso (CAGNINE, Décio, 2018, p. 23, 24).

Logo de início Décio nos apresenta uma interpretação interessante e significativa sobre a falta de perspectiva para a permanência dos filhos de agricultores no meio rural, principalmente daqueles filhos de pequenos camponeses. Isso acaba ocasionando o cenário descrito por Décio, o grande proprietário "granjeiro" fica na espera da aposentadoria do pequeno agricultor, de algum problema de saúde ou financeiro que facilite a compra da propriedade. Para o entrevistado esse não só é o grande interesse dos latifundiários da região, mas também do próprio governo, que busca representar esse setor e incentivar seu desenvolvimento.

Notamos assim, de que maneira, na continuidade de sua narrativa, Décio atrela as questões políticas com as conjunturas econômicas e sociais apresentadas à agricultura da região. Em sua opinião, a retração das políticas públicas para os pequenos e médios agricultores, o vertiginoso crescimento do agronegócio, desembocam na migração dos filhos de agricultores para o ambiente urbano, local em que constituíram experiências enquanto trabalhadores no setor agroindustrial ou industrial. Tal ligação, para Décio, explica a não alteração das bases políticas brasileiras, já que o empregado urbano acaba ficando submisso a ordem patronal, que inserido na cena pública política faz com que os ex-agricultores se tornem votos para não apenas manter a estrutura agrária e fundiária brasileira da maneira como está, mas também, para acentuar as desigualdades sociais.

Notoriamente, Décio elabora essas análises e considerações tomando como base não só a região Sudoeste do Paraná, mas as conjunturas gerais que regram a agricultura brasileira na contemporaneidade. É claro que a região em que reside é a sua grande referência, até por isso, decido interrogá-lo para que expresse de maneira mais apurada como percebe a organização fundiária da região em contexto recente:

[...] não precisa nem fazer pesquisa, o agronegócio é assim, aquele que tinha há 10 anos atrás 100 alqueires, hoje ele tem 300! Aquele que tinha. Lavoura e gado, lavoura e gado e aquele que tinha, aqui o pai quando veio do Rio Grande ele tinha, eu acho que tinha 50 hectares, eu tenho nove, dez, então a tendência é esmiúça ou 
ficar menor o do pequeno e do grande ficar maior, ponto. É isso (CAGNINE, Décio, 2018, p. 24).

O avanço do agronegócio no Sudoeste do Paraná é tão evidente que "não precisa nem fazer pesquisa". Complementa essa constatação afirmando que o agronegócio assenta sua base na lavoura - sobretudo soja e milho - e no gado, assim, salienta que existe um evidente crescimento desse setor, chegando a citar como exemplo a propriedade de seu pai, que era de aproximadamente 50 hectares e hoje tem apenas nove, que é a fração de terra que o próprio entrevistado ocupa. Nesse sentido, Décio afirma que se há “10 anos atrás” um agricultor possuía 100 alqueires na região, hoje ele já tem mais de 300 .

Expõe em seguida elementos de suas experiências diárias para enfatizar a compra de pequenas e médias propriedades por agricultores vinculados ao agronegócio. Assim, menciona que: "muitas casas que eu vou na, praticamente na região toda, onde tinha casas, moradores, as casas tão, em muitos lugares você vê aquelas casonas bonitas abandonadas lá no meio da granja, eles fizeram granja, lavoura!”. Complementa sua argumentação enfatizando que "só não derrubaram a casa ainda, mas não tem nada: 'ali esses tempo tinha uma casa, derrubaram tá tudo granja"” (CAGNINE, Décio, 2018, p. 24).

É interessante notar de que maneira Décio traz elementos da sua experiência diária para dar validade as suas constatações, nesse caso, enfatiza o avanço do agronegócio sobre as pequenas e médias propriedades rurais, ao salientar que as lavouras - possivelmente de soja e milho - tomam toda a extensão das propriedades, com exceção da área onde se encontram as casas. Para Décio, esse exemplo oferece um interessante contraste, já que coloca "aquelas casonas bonitas abandonadas lá no meio da granja", além é claro de representar a migração do campo para a cidade.

Mas, as constatações do entrevistado não se restringem a esses elementos, também destaca que:

[...] tá sumindo as propriedades, elas vão ficando, aquelas que têm pequenas elas vão ficando cada vez mais pequenas e aquelas grandes vão ficando mais grande. Aqui no Verê eu sei que tinha mil e poucas propriedades rurais, eu não sei se tem 800,700 , porque tá caindo (CAGNINE, Décio, 2018, p. 24, 25).

Um ponto que cabe fazer algumas considerações nesse momento é em relação ao financiamento agrícola, em entrevista realizada com o diretor do Capa de Verê Jhony Luchmann, o entrevistado salientou que existem inúmeras dificuldades para pequenos agricultores conseguirem financiamentos de implementos agrícolas e de custeio de lavouras. 
De acordo com Luchmann, existem dificuldades para os pequenos agricultores, já que as cooperativas de crédito dão preferência para aqueles que buscam financiamentos mais vultosos, para lavouras de soja e milho.

Para Luchmann esse é um dos pontos fundamentais do avanço do agronegócio na região, ao passo que, apesar de Décio admitir as dificuldades dos pequenos e médios agricultores, não atrela o avanço do agronegócio a falta de crédito agrícola e consequentemente financiamentos aos pequenos agricultores. Isso se deve, muito provavelmente, por que o entrevistado tem boas relações com as cooperativas de crédito, o que faz com que tenha facilidades nesse sentido, não mencionando problemas, quando indagado sobre os financiamentos agrícolas para pequenos e médios agricultores.

Outro aspecto apontado por Décio, que cabe fazer algumas considerações é em relação à queda no número de propriedades no município de Verê, o que significa um claro exemplo de concentração fundiária. É evidente que para ter uma argumentação mais substancial em relação a isso seria necessário realizarmos um levantamento de todos os municípios da região e apurar qual o real decréscimo das pequenas e médias propriedades agrícolas em consequência da ação do agronegócio.

Também foi possível notar que, esses processos não são automáticos e tampouco acontecem com a naturalidade exposta por nosso entrevistado. Grande parte do que Décio narrou também pode estar relacionado a práticas agrícolas agronegociantes, sem que o agricultor tenha necessariamente, que vender sua pequena ou média propriedade. Remeto nesse momento a atuação das cooperativas agrícolas e de crédito, que, possuem uma significativa inserção entre os pequenos e médios agricultores, fazendo com que pratiquem uma agricultura conhecida como “Agronegocinho", isto é, práticas agrícolas, com o plantio de monoculturas como soja e milho em suas pequenas e médias propriedades.

Isso acontece tanto de forma direta pelo próprio agricultor, que consegue financiar suas culturas e alguns implementos essenciais para o plantio. Como também na forma de arrendamento. Muitos médios agricultores acabam arrendando terras de pequenos, na maioria das vezes seus vizinhos. O próprio Décio nos dá elementos para confirmar essas questões, quando narra sobre o crescimento e inserção das cooperativas "do agronegócio" na região:

Assim, essas com certeza não vão parar, vai crescer, vai crescer porque elas têm inúmeras vantagens em relação ao, as outras empresas que compram e vendem insumos e sementes, porque as cooperativas se a gente for ver elas tem uma série de vantagens, por exemplo, essa questão do biodiesel, essa questão do biodiesel tudo tem que passar por uma cooperativa, tem que passar por uma cooperativa, senão não pode, e cada cooperativa, por exemplo, um saco de soja passando pela cooperativa 
ela vai ganhar um real e meio a mais do preço que as outras empresas pagam, entendeu? Então, se sócio de uma cooperativa hoje e pode colocar a DAP [Declaração de Aptidão ao Pronaf] lá e plantar soja pra entregar na [cooperativa] você já tem um real e meio a mais por saca, o cara que colhe 10 mil sacas é 15 mil reais a mais, assim, trabalhando no mesmo nível (CAGNINE, Décio, 2018, p. 26).

É exatamente essa conjuntura que faz com que a estrutura agrária da região variedade de culturas agrícolas cultivadas - tenha se modificado de forma rápida e significativa, com o avanço e predominância, quase que exclusiva, de culturas voltadas ao agronegócio. Já a estrutura fundiária - variação no número de propriedades e em sua extensão - tem sofrido variações, tivemos um evidente decréscimo no número de propriedades, que corrobora com um notável crescimento da concentração fundiária.

Nesse sentido, não podemos negar que existem permanências e rupturas na estrutura agrária e fundiária da região, permanências como uma, ainda significativa, presença de pequenas e médias propriedades assentadas, na produção orgânica, leiteira ${ }^{6}$ e do famoso “Agronegocinho". Em contraste com as rupturas, a diminuição já evidente no número de pequenas e médias propriedades.

Desta maneira, podemos ponderar que existem diferentes representações de agricultura familiar e pequenas propriedades na região. O Capa, a Coopervereda e as outras entidades que apoiam e promovem a agricultura familiar e orgânica se baseiam na conceitualização do Estado para sua delimitação de pequenas propriedades. Curiosamente é essa mesma delimitação - de quatro módulos fiscais - permite que grande parte dos agricultores da região produzir monoculturas como soja e milho com vistas ao mercado externo, dentro de linhas de crédito para a agricultura familiar.

Dentro do enquadramento de pequenas propriedades e agricultura familiar no Sudoeste do Paraná, conseguimos notar distintas representações sociais do espaço, que sugerem a estes agricultores diferentes espaços, onde cada grupo social reproduz suas experiências de acordo com a conjuntura que lhe é apresentada. Este contexto reforça ainda mais a noção de que a estruturação agrária e fundiária recente deste espaço é marcada por heterogeneidades sociais.

\section{Considerações finais}

\footnotetext{
${ }^{6}$ Apesar da sua retração na última década, a produção leiteira ainda se faz muito presente na região Sudoeste do Paraná, para maiores esclarecimentos ver: RIPPEL, Leomar; ALVES, Adilson Francelino. PLEIN, Clério. O cooperativismo de leite da agricultura familiar no Sudoeste do Paraná: do processo organizacional à crise. IGEPEC. Toledo-PR, v.22, n.1, jan./jun. 2018.
} 
Após a análise das fontes, podemos concluir previamente que Décio e Izolete procuram recriar suas vivências enquanto camponeses dentro das relações econômicas e sociais apresentadas pelo capitalismo. Curiosamente são essas relações tipicamente capitalistas que os faz permanecer na agricultura e cultivar seus alimentos orgânicos, ou seja, mesmo que apresentem certa criticidade a organização da sociedade a partir do modelo capitalista é esse mesmo modelo que os permite recriar-se e adaptar-se na agricultura da região.

Em relação às dificuldades encontradas pelo casal, elas expõem-se enquanto fruto das próprias dinâmicas capitalistas apresentadas à agricultura brasileira nas últimas décadas. A agricultura praticada por Décio e Izolete, apesar de estar inserida na economia regional, não tem o mesmo prestígio da agricultura vista e entendida como de agronegócio, que tem maiores facilidades econômicas e políticas, que facilitam sua inserção e avanço no Sudoeste do Paraná.

Mesmo assim, o exemplo aqui destacado demonstra de que maneira a estrutura fundiária de pequenas propriedades da região pode ser apropriada por experiências agrícolas orgânicas e agroecológicas. Além do mais, também evidencia as diferentes camadas de agricultores que constituem esse espaço, além de ressaltar o protagonismo dos camponeses Décio e Izolete em suas práticas agrícolas.

\section{Referências}

KAUTSKY, Karl. A questão agrária. São Paulo - SP: Editora Proposta, 1980.

LÊNIN, Vladimir Ilitch. O desenvolvimento do Capitalismo na Rússia: o processo de formação do mercado interno para a grande indústria. 2. Ed. São Paulo: Nova Cultural, 1985.

MARTINS, José de Souza. Os Camponeses e a política no Brasil: As lutas sociais no campo e seu lugar no processo político. Petrópolis, $5^{\circ}$ Edição: Editora Vozes, 1995.

OLIVEIRA, Ariovaldo Umbelino de. Modo de Produção Capitalista, Agricultura e Reforma Agrária. São Paulo: Labur Edições, 2007.

RIPPEL, Leomar; ALVES, Adilson Francelino. PLEIN, Clério. O cooperativismo de leite da agricultura familiar no Sudoeste do Paraná: do processo organizacional à crise. IGEPEC. Toledo-PR, v.22, n.1, jan./jun. 2018.

SHANIN, Teodor. A definição de camponês: conceituações e desconceituações - o velho e o novo em uma discussão marxista. Revista Nera. Ano 8, n. 7 - julho/dezembro de 2005.

VANDERLINDE, Tarcísio. Região. In: MOTTA, Márcia (org.). Dicionário da terra. Rio de Janeiro: Civilização Brasileira, 2005. 


\section{Fontes}

CAGNINE, Décio; CAGNINE, Izolete Bornhofen. Entrevista concedida a Tiago A. Orben. Comunidade rural de Vila Colonial, Verê/PR: 21 de maio de 2018, duração: 01h 26min. 02segs. 